\title{
Bird pollinators differ in their tolerance of a nectar alkaloid
}

\author{
Sara Lerch-Henning ${ }^{*}$ and Susan W. Nicolson \\ Department of Zoology and Entomology, University of Pretoria, Pretoria 0002, South Africa
}

*Author for correspondence:

S. Lerch-Henning

Department of Zoology and Entomology

University of Pretoria

Pretoria 0002, South Africa

Tel: +27 124205343

Fax: +27 123625242

Email: slerch@zoology.up.ac.za 
Although the function of nectar is to attract and reward pollinators, secondary metabolites (SM) produced by plants as anti-herbivore defences are frequently present in floral nectars. Greater understanding is needed of the effects of SM in nectar on the foraging behavior and performance of pollinators, and on plant-pollinator interactions. We investigated how nectarfeeding birds, both specialist (white-bellied sunbirds Cinnyris talatala) and generalist (darkcapped bulbuls Pycnonotus tricolor and Cape white-eyes Zosterops virens), respond to artificial nectar containing the alkaloid nicotine, present in nectar of Nicotiana species. Preference tests were carried out with a range of nicotine concentrations (0.1-300 $\mu \mathrm{M})$ in two sucrose concentrations $(0.25$ and $1 \mathrm{M})$. In addition, we measured short-term feeding patterns in white-bellied sunbirds that were offered nicotine $(0-50 \mu \mathrm{M})$ in $0.63 \mathrm{M}$ sucrose. Both nicotine and sugar concentrations influenced the response of bird pollinators to nicotine. The birds showed dose-dependent responses to nicotine; and their tolerance of high nicotine concentrations was reduced on the dilute $0.25 \mathrm{M}$ sucrose diet, on which they increased consumption to maintain energy intake. White-bellied sunbirds decreased both feeding frequency and feeding duration as the nicotine concentration in artificial nectar increased. Of the three species, bulbuls showed the highest tolerance for nicotine, and sugar type (sucrose or hexose) had no effect. The indifference of bulbuls to nicotine may be related to their primarily frugivorous diet. Additional testing of other avian nectarivores and different SM is required to further elucidate whether generalist bird pollinators, which utilise dilute nectars in which SM have stronger deterrent effects, are more tolerant of 'toxic' nectar. 
The occurrence of secondary metabolites (SM) in nectar has been reported in at least 21 angiosperm families (Adler 2000). Little is known about the significance of these nectar components in plant-pollinator relationships, or about the possible trade-offs between defence and attraction (Strauss 1997, Irwin et al. 2004, Kessler and Halitschke 2009). Various hypotheses have been proposed to explain the apparent paradox of deterrent compounds in a pollinator attractant (Adler 2000). For example, SM in nectar could attract effective pollinators while deterring nectar robbers or inefficient pollinators (Stephenson 1982, Johnson et al. 2006). Deterrence of effective pollinators might also benefit plant reproduction if unpalatable nectar shortens visit time and encourages pollinators to move between plants (Kessler et al. 2008). Alternatively, SM could help to protect nectar from degradation due to microorganisms such as yeasts (Irwin et al. 2004, Herrera et al. 2008); and there is some evidence that SM in nectar could have indirect benefits by reducing the pathogen loads of pollinators (Manson et al. 2010). Not to be excluded is the possibility that SM are present in nectar as a pleiotropic consequence of plant defence chemistry. This nonadaptive hypothesis leads to the prediction, partially supported by recent studies of Nicotiana and Asclepias, that defensive chemistry of nectar, flowers and leaves will be similar (Adler et al. 2012, Manson et al. 2012).

Pollinators are generally repelled by artificial nectar containing compounds from the major SM classes of alkaloids and phenolics. High concentrations of various SM have been found to reduce food consumption of honeybees Apis mellifera (Detzel and Wink 1993, Hagler and Buchmann 1993, Singaravelan et al. 2005, London-Shafir et al. 2003). However, the responses of pollinators are dose-dependent as well as varying with the secondary chemistry (Detzel and Wink 1993). Low doses may have an attractant effect: bees prefer low concentrations of phenolics (Hagler and Buchmann 1993) and alkaloids (Singaravelan et al. 2005) to a pure sucrose solution. Not surprisingly, different pollinators may show varying reactions to the same compound in nectar: for example, Johnson et al. (2006) found that honeybees and amethyst sunbirds Chalcomitra amethystina reject Aloe vryheidensis nectar containing phenolics, but Cape white-eyes Zosterops virens and dark-capped bulbuls Pycnonotus tricolor consume this nectar in feeding trials. 
The pyridine alkaloid nicotine, highly toxic and deterrent to herbivores, is one of the beststudied SM in terms of plant defence (Steppuhn et al. 2004). More information is available on concentrations of tobacco alkaloids in floral nectar of Nicotiana (Solanaceae) than for any other nectar SM. In a recent study of defensive chemistry of 32 Nicotiana species (Adler et al. 2012), measured nectar nicotine concentrations ranged from 0-33 $\mu \mathrm{M}$ (3.72 $\pm 1.18 \mu \mathrm{M}$; mean \pm SE) and concentrations of the related alkaloid anabasine from $0-12 \mu \mathrm{M}(1.07 \pm 0.51 \mu \mathrm{M})$. These authors showed that levels of nicotine in nectar, leaf and floral tissues were positively correlated with each other and with reliance on pollinators, but no such pattern was evident for anabasine. Other measurements of nectar nicotine concentrations have yielded mean values ranging from 3 - $42 \mu \mathrm{M}$ in N. glauca, N. attenuata and N. quadrivalvis (Tadmor-Melamed et al. 2004, Kessler et al. 2012, Halpern et al. 2010), and sampling from different populations of $N$. attenuata has highlighted great variability in nectar nicotine concentrations, even under greenhouse conditions (Kessler et al. 2012). The genus Nicotiana is largely confined to the Americas and Australia, and its main pollinators appear to be hummingbirds and Lepidoptera (Kaczorowski et al. 2005, Raguso et al. 2003); however, the responses of birds and insects to nectar nicotine have not been investigated in detail. Free-flying honeybees tolerate low nicotine concentrations, even preferring them to sucrose-only solutions (Köhler et al. 2012, Singaravelan et al. 2005). A field experiment with hummingbirds Archilochus alexandri showed that these birds were repelled by $50 \mu \mathrm{M}$ but not $25 \mu \mathrm{M}$ nicotine (Kessler et al. 2012). Palestine sunbirds Cinnyris oseus, however, were deterred by only $3 \mu \mathrm{M}$ nicotine, the mean concentration in N. glauca flowers sampled in Israel (Tadmor-Melamed et al. 2004). This Argentinian species, adapted for pollination by hummingbirds (Nattero and Cocucci 2007), is a widespread invasive plant. In South Africa, as in Israel, it is a valuable nectar resource in dry regions and is visited and pollinated by sunbirds (Geerts and Pauw 2009, Skead 1967).

The responses of birds to nectar SM may depend on the degree of specialisation on a nectar diet. Hummingbirds and sunbirds are specialist pollinators that visit flowers with small volumes of moderately concentrated nectar containing a high proportion of sucrose, but plants that are mostly pollinated by generalist avian nectarivores produce larger volumes of very dilute nectar with mostly hexose sugars (Johnson and Nicolson 2008). Occasional or generalist avian nectarivores include weavers, bulbuls, orioles, and white-eyes, and have shorter bills and 
larger body sizes than specialists (Symes et al. 2008). For these birds, nectar is a supplement to their typical diets of fruit, insects and seeds in varying proportions depending on season. It has recently been pointed out that paracellular absorption of water-soluble SM (such as nicotine) is likely to be high in birds, leading to rapid accumulation of toxins in the gut (Karasov et al. 2012). On the other hand, avian frugivores may be relatively tolerant to dietary SM, compared to other birds (Cipollini and Levey 1997).

We investigated the nicotine tolerance of three bird pollinators: a specialist nectar-feeder, the white-bellied sunbird Cinnyris talatala, and two generalist nectar-feeders, dark-capped bulbuls P. tricolor and Cape white-eyes Z. virens. The effect of nicotine on food consumption was assessed in dose-response experiments with sucrose and glucose-fructose solutions at two concentrations (low and high) containing different nicotine concentrations (0.1-300 $\mu \mathrm{M})$. We also investigated the effect of nicotine $(0.5-50 \mu \mathrm{M})$ on short-term feeding patterns of sunbirds. The following predictions were tested: (1) for all three bird species, nicotine tolerance will decrease as nicotine concentration increases; (2) higher sugar concentration will increase their nicotine tolerance; (3) sunbirds will have a lower nicotine tolerance than the two generalist nectar-feeding species; (4) bulbuls, which utilise hexose-based nectars, will tolerate nicotine better if mixed in hexose than in sucrose, and (5) feeding frequency and feeding duration of sunbirds will vary with the concentration of nicotine in nectar.

\section{Material and methods}

\section{Study animals and their maintenance}

Ten white-bellied sunbirds (mean body mass $\pm \mathrm{SE}=8.71 \pm 0.35 \mathrm{~g}$ ) and seven Cape white-eyes (10.93 \pm 0.16 g) were mist-netted in Jan Cilliers Park, Pretoria. We later captured a second group of nine white-bellied sunbirds ( $8.54 \pm 0.37 \mathrm{~g}$ ) for examination of feeding patterns. Nine dark-capped bulbuls (39.6 \pm 0.80 g) were captured with spring-traps at the Experimental Farm of the University of Pretoria. Birds were captured during the non-breeding season; sunbirds in 2009 and again in 2011, bulbuls and white-eyes in 2010. All birds were released at the place of 
capture after experiments were completed. Birds were acclimatised to captivity for three weeks in outdoor aviaries covered with shade-cloth.

The maintenance diet consisted of a $0.63 \mathrm{M}$ sucrose solution with a nutritional supplement for protein, vitamins and minerals (Ensure ${ }^{\circledR}$, Abbott Laboratories, Johannesburg, South Africa). In addition to the artificial nectar, white-eyes and bulbuls received seasonal fruits such as papaya, apples and bananas as well as moistened ProNutro ${ }^{\circledR}$ cereal (Becketts CNR, Wadeville, South Africa) provided in feeding trays attached to the side of the aviary. Food and water were presented ad libitum and renewed daily. Modified syringes $(20 \mathrm{ml})$ were used as feeders for the artificial nectar and water provided to sunbirds and white-eyes. The syringes were blocked and a hole of 2-3 mm in diameter was made on the side and painted with red nail varnish around the drinking aperture. Bulbuls were provided with classic pet bird feeders. Water baths were present in both aviaries.

Before experiments, we moved sunbirds and white-eyes to individual cages $(30 \times 42 \times 46 \mathrm{~cm}$ ) with wooden perches, kept in a climate-controlled room maintained at $20 \pm 2{ }^{\circ} \mathrm{C}$ on a $12: 12 \mathrm{~h}$ light : dark photocycle with lights on at 07h00. Dawn and dusk were simulated with $0.5 \mathrm{~h}$ of dimmed light at the beginning and the end of the light period. The maintenance diet was the same as above. Experiments involving bulbuls were carried out in the aviary with birds transferred to individual cages $(1 \times 1 \times 1 \mathrm{~m})$ attached to one side of the aviary and containing wooden perches.

\section{Experimental procedure: nicotine tolerance}

Trials were carried out with either 0.25 or $1 \mathrm{M}$ sucrose as the base solution. In pair-wise preference tests, sunbirds and white-eyes were given a choice between a control solution (sucrose solution only) and a test diet: one of nine nicotine (Sigma; (-)-nicotine, N3876) concentrations ranging from 0.1 to $300 \mu \mathrm{M}$ mixed in the same sucrose concentration as the control. For bulbuls, the trials were run using seven nicotine concentrations $(0.3-300 \mu \mathrm{M})$ mixed in the two sucrose solutions and, additionally, mixed into a 1:1 glucose:fructose mixture ("hexose") at two different concentrations (0.25 and $1 \mathrm{M}$ sucrose equivalents). All solutions 
(control solution and test diets) were prepared in advance and frozen until use. Each bird was tested with all possible combinations and the sequence of test diet and base solution was randomised. White-eyes and bulbuls received no fruit during trials.

For sunbirds, the duration of the experiment was $3 \mathrm{~h}$, from $09 \mathrm{~h} 00$ to $12 \mathrm{~h} 00$, when food consumption of captive sunbirds is highest (Köhler et al. 2006). The same nicotine concentration was offered on two consecutive days, with the position of the feeder switched on the second day to allow for possible side bias (Jackson et al. 1998). The protocol for white-eyes and bulbuls differed, in that experiments lasted from $08 \mathrm{~h} 00$ to $14 \mathrm{~h} 00$, with the position of the feeders being switched every $1.5 \mathrm{~h}$.

Food consumption (g) was recorded by weighing the feeders before and after every trial $( \pm 0.1$ mg, Mettler Toledo AG-64, Microsep Ltd, Johannesburg). Any drips from feeders were collected in plastic cups containing liquid paraffin (to avoid evaporation); these were weighed at the same time as feeders and food consumption corrected accordingly. The nicotine tolerance index was expressed as the intake of each test diet as a proportion of total food intake, where a value of 0.5 indicates nicotine tolerance.

Because the energy intake of bulbuls is much greater than for the other two species, we considered nicotine intake in relation to sucrose intake for the two highest nicotine concentrations (100 and $300 \mu \mathrm{M})$. We calculated nicotine intake $(\mu \mathrm{g})$ as the product of volumetric intake of test diet and nicotine concentration, and sucrose intake (g) as the product of volumetric food intake and sucrose concentration. Volumetric intake (ml) was calculated by dividing food consumption (g) by the relative density of the sucrose solution.

\section{Experimental procedure: short-term feeding patterns}

Sunbirds were presented with a control solution ( $0.63 \mathrm{M}$ sucrose) and three nicotine concentrations ( $0.5,5$ and $50 \mu \mathrm{M}$ nicotine in $0.63 \mathrm{M}$ sucrose) in random order. Trials lasted $6 \mathrm{~h}$ (from $8 \mathrm{~h} 00$ to $14 \mathrm{~h} 00$ ) and were followed by at least one day of maintenance diet. We recorded

food intake by weighing feeders as above, and converted it to sugar intake (g). An infrared 
photo-detection system was mounted on both side of the feeder to record feeding events, and was interfaced to a computer (Köhler et al. 2006). The number of feeding events, the duration of each feeding event (s) and the total time spent feeding (s) were recorded. The settings for the recording were as follows: feeding events of less than 0.05 s were excluded and consecutive feeding events were merged into a single feeding event if the interval between them was less than $0.25 \mathrm{~s}$; this is because the photo-detectors are very sensitive to movements of the bird or incomplete removal of the bill (Köhler et al. 2006).

\section{Statistical analysis}

Analysis of arcsine square root-transformed nicotine tolerance was carried out by generalized linear models (Wald chi-square tests) with $\mathrm{IBM}_{\circledast}$ SPSS Statistics program (version 19) because the data were non-normally distributed and heteroscedastic. For sunbirds, we averaged food intake for each feeder (control and test diet) over the two consecutive days because the total food consumption between days was not significantly different (repeated measures ANOVA: $\mathrm{F}_{1,9} \leq 7.09, \mathrm{p} \geq 0.03$ ). For each species separately, the effect of nicotine concentration ( $\mathrm{N}=9$ for sunbirds and white-eyes, $\mathrm{N}=7$ for bulbuls) on nicotine tolerance was tested. We also tested the following: the effect of sucrose concentration on nicotine tolerance and the interaction of nicotine and sugar concentration (nicotine conc.*sucrose conc.); the effect of sugar type on nicotine tolerance of bulbuls; the effect of bird species, separately for the two sucrose concentrations, on nicotine tolerance; and the effect of bird species and nicotine concentration on nicotine intake $(\mu \mathrm{g}) /$ sugar intake (g). Post-hoc comparisons for generalized linear models were determined by Bonferroni correction. Lastly, nicotine tolerance of the three bird species, at each nicotine concentration, was analysed by comparing the arcsine-transformed square root of nicotine tolerance index against 0.5 (indicating tolerance) by one-sample t-test.

The data for short-term feeding patterns were also non-normally distributed and heteroscedastic, and were analysed by generalized linear models (Wald chi-square tests). The effect of nicotine concentration $(\mathrm{N}=4)$ on the three parameters separately (mean feeding duration, feeding frequency and total feeding time) was tested. Post-hoc comparisons were 
determined by a Bonferroni correction. Data are presented as mean values \pm SE and the level of significance was $\mathrm{p}<0.05$.

\section{Results}

\section{Nicotine tolerance}

Birds did not tolerate high nicotine concentrations in artificial diets. The decrease in nicotine tolerance as nicotine concentration increased was most marked for the lower sucrose concentration, where birds would have to ingest greater volumes (and therefore more nicotine) to maintain energy balance (Fig 1).

Nicotine concentration had a significant effect on nicotine tolerance in white-bellied sunbirds for both sucrose concentrations $\left(0.25 \mathrm{M}\right.$ : Wald $\chi^{2}=4571.79$, df $=8, \mathrm{p}<0.001$; and $1 \mathrm{M}$ : Wald $\chi^{2}=384.09$, df $=8, \mathrm{p}<0.001$; nicotine conc. ${ }^{*}$ sucrose conc.: Wald $\chi^{2}=104.88$, df $=9, \mathrm{p}<0.001$ ). When nicotine was mixed in 0.25 M sucrose, the five lowest nicotine concentrations (0.1-7 $\mu \mathrm{M}$ ) were tolerated by the birds, but not the concentrations ranging from 15-300 $\mu \mathrm{M}$ (see Table 1 for statistical values). When nicotine was mixed in $1 \mathrm{M}$ sucrose, birds avoided only the two highest nicotine concentrations: therefore, the deterrent effect of nicotine was stronger in the dilute sucrose solution (Wald $\chi^{2}=116.75$, $\mathrm{df}=1, \mathrm{p}<0.001$ ).

The same nine nicotine concentrations were tested on Cape white-eyes, with a significant effect on nicotine tolerance in both sucrose concentrations $\left(0.25 \mathrm{M}\right.$ : Wald $\chi^{2}=85.58$, $\mathrm{df}=6$, $\mathrm{p}<$ 0.001; and $1 \mathrm{M}$ : Wald $\chi^{2}=1031.87$, df $=6, \mathrm{p}<0.001$; nicotine conc.* sucrose conc.: Wald $\chi^{2}=110.71$, df $\left.=6, \mathrm{p}<0.001\right)$. Birds showed tolerance for the four lowest $(0.1-3 \mu \mathrm{M})$ nicotine concentrations when nicotine was mixed in $0.25 \mathrm{M}$ sucrose. In the sweeter solution, birds showed tolerance for $0.1,0.6$ and $15 \mu \mathrm{M}$ nicotine (see Table 1 for statistical values). As in sunbirds, the deterrent effect of nicotine was stronger in the dilute sucrose solution (Wald $\chi^{2}=$ 11.34, $\mathrm{df}=1, \mathrm{p}=0.001$ ). 
In bulbuls, nicotine concentration had a significant effect on nicotine tolerance (Wald $\chi^{2}=$ 125.4, $\mathrm{df}=6, \mathrm{p}<0.001$ ) but sucrose concentration did not (Wald $\chi^{2}=3.42$, df $=1, \mathrm{p}=0.065$; nicotine conc. $*$ sucrose conc.: Wald $\chi^{2}=38.15$, df $\left.=8, \mathrm{p}<0.001\right)$. When nicotine was mixed in hexose, nicotine concentration (Wald $\chi^{2}=255.9$, $\mathrm{df}=6, \mathrm{p}<0.001$ ) and hexose concentration (Wald $\chi^{2}=12.58$, df $=1, \mathrm{p}<0.001$; nicotine conc. ${ }^{*}$ sucrose conc.: Wald $\chi^{2}=206.52$, df $=8$, $\mathrm{p}<0.001$ ) had a significant effect on nicotine tolerance (Fig. 2). The same nicotine tolerance was found when nicotine was mixed in sucrose or hexose, with one exception; bulbuls did not tolerate $300 \mu \mathrm{M}$ nicotine mixed in $1 \mathrm{M}$ sucrose (for statistical values see Table 1). No significant difference was found when comparing nicotine tolerance between sucrose and hexose (separately for concentration; $0.25 \mathrm{M}$ sucrose equivalent: Wald $\chi^{2}=1.77$, $\mathrm{df}=1, \mathrm{p}=$ 0.184 and $1 \mathrm{M}$ sucrose equivalent: Wald $\chi^{2}=0.059$, $\mathrm{df}=1, \mathrm{p}=0.808$ ).

Nicotine tolerance differed significantly with bird species $\left(0.25 \mathrm{M}\right.$ sucrose: Wald $\chi^{2}=65.51$, $\mathrm{df}$ $=2, \mathrm{p}<0.001 ; 1 \mathrm{M}$ sucrose: Wald $\chi^{2}=30.32, \mathrm{df}=2, \mathrm{p}<0.001$ ), where bulbuls showed the highest nicotine tolerance followed by sunbirds and white-eyes. The nicotine tolerance of the two generalist nectar-feeding birds differed considerably; bulbuls consumed more of nicotinecontaining diets than white-eyes $\left(0.25 \mathrm{M}\right.$ sucrose: Wald $\chi^{2}=23.758$, $\mathrm{df}=1, \mathrm{p}<0.001 ; 1 \mathrm{M}$ sucrose: Wald $\chi^{2}=27.802$, df $\left.=1, \mathrm{p}<0.001\right)$. Interestingly, the nicotine tolerance of whiteeyes was lower (significant only in $1 \mathrm{M}$ sucrose: Wald $\chi^{2}=6.14, \mathrm{df}=1, \mathrm{p}=0.013$ ) than that of sunbirds.

We compared nicotine intake $(\mu \mathrm{g}) /$ sugar intake (g) for the two highest nicotine concentrations used (100 and $300 \mu \mathrm{M})$ and all three species (Fig. 3). Bird species had a significant effect (0.25 M sucrose: Wald $\chi^{2}=17.41, \mathrm{df}=2, \mathrm{p}<0.001 ; 1 \mathrm{M}$ sucrose: Wald $\chi^{2}=10.22$, $\mathrm{df}=2, \mathrm{p}<$ 0.006). In 0.25 M sucrose, bulbuls consumed significantly more nicotine for a given sugar intake than sunbirds (100 $\mu \mathrm{M}$ and $300 \mu \mathrm{M} ; \mathrm{p}<0.001$ and $\mathrm{p}=0.02$ respectively) or white-eyes ( $\mathrm{p}<0.001$ and $\mathrm{p}=0.03)$. When nicotine was mixed in $1 \mathrm{M}$ sucrose, the only significant difference was the higher nicotine/sugar intake of bulbuls than of white-eyes on $100 \mu \mathrm{M}$ nicotine $(\mathrm{p}<0.001)$.

\section{Short-term feeding patterns}


White-bellied sunbirds presented with $0.63 \mathrm{M}$ sucrose solution had a mean feeding duration of $0.53 \mathrm{~s}$, a mean feeding frequency of 233 events $\mathrm{h}^{-1}$ and the total time spent feeding was $1.5 \mathrm{~min}$

$\mathrm{h}^{-1}$. Nicotine concentration had a significant effect on sugar intake during the $6 \mathrm{~h}$ trial (Wald $\chi^{2}$ $=303.81, \mathrm{df}=3, P<0.001)$. Sugar intake on $5 \mu \mathrm{M}$ nicotine was significantly lower than that on control and $0.5 \mu \mathrm{M}$ nicotine diets $(P<0.001)$, and sugar intake on $50 \mu \mathrm{M}$ nicotine was lower than on all other diets $(P<0.001)$. This effect of nicotine concentration was reflected in short-term feeding patterns: with increasing nicotine concentration, feeding frequency (Wald $\chi^{2}$ $=40.06, \mathrm{df}=3, P<0.001)$ and total feeding time (Wald $\chi^{2}=37.43, \mathrm{df}=3, P<0.001$ ) decreased significantly (Fig. 4). Feeding frequency of birds feeding on $50 \mu \mathrm{M}$ nicotine in 0.63 M sucrose was lower than when feeding on the control diet $(P=0.004)$ or low and medium nicotine $(P<0.001)$; there were no significant differences between control, low and medium nicotine. A similar pattern was found for total feeding time: for birds presented with a high nicotine concentration it was lower than for the control solution and low and medium nicotine concentrations $(\mathrm{p}<0.001)$; no other diets differed significantly. The overall effect of nicotine concentration on feeding duration (Wald $\chi^{2}=25.40, \mathrm{df}=3, P<0.001$ ) was significant (Fig 4): high nicotine concentration decreased feeding duration. However, there were no significant differences between the diets (control solution vs high nicotine: $P=0.078$ ).

\section{Discussion}

The presence of secondary metabolites in nectar is puzzling: are SM present in nectar only as a consequence of protection against herbivores or do they have an evolutionary significance and influence interactions with pollinators? We have demonstrated that the nicotine tolerance of three bird pollinators depends on both the nicotine and sugar concentrations of artificial nectar. Bulbuls, like other generalist nectarivores, consume very dilute nectars but have the highest nicotine tolerance of the species we investigated, irrespective of nectar sugar composition. We discuss these findings in terms of nectar composition, specialisation and generalisation in bird pollination systems, and the implications of differing SM tolerance for the behaviour of birds at flowers. 
Sugar concentration of the artificial nectar had a marked effect on the responses to nicotine. While white-bellied sunbirds tolerated nicotine at $3 \mu \mathrm{M}$ in $0.25 \mathrm{M}$ sucrose, their tolerance increased to $40 \mu \mathrm{M}$ in $1 \mathrm{M}$ sucrose. These sunbirds are apparently more tolerant of nicotine in sucrose solution than Palestine sunbirds, which tolerated nicotine at $0.6 \mu \mathrm{M}$ but not $3 \mu \mathrm{M}$ in 0.63 M sucrose (Tadmor-Melamed et al. 2004). Blackchinned hummingbirds Archilochus alexandrei were not deterred by $N$. attenuata nectar containing an average nicotine concentration of $31 \mu \mathrm{M}$ in a sugar concentration of $0.5 \mathrm{M}$ (Kessler et al. 2010), and feeder trials with the same hummingbird species showed deterrence only at $50 \mu \mathrm{M}$ nicotine in $0.91 \mathrm{M}$ sucrose (Kessler et al. 2012). Increasing sugar concentration is likely to mask the bitter taste of alkaloids, and a sweeter solution is also a more profitable diet that pollinators might choose to consume despite the presence of SM. The same pattern has been found with blowflies where an increase in sucrose concentration decreased the deterrent effect of quinine (Moss and Dethier 1983). Likewise, in an experiment with bumblebees Bombus impatiens, the deterrent effect of the alkaloid gelsemine was reduced by increasing the sucrose concentration from $1 \mathrm{M}$ to $1.8 \mathrm{M}$ (Gegear et al. 2007). Similar results have been found for honeybees, where an increase in the sugar concentration of artificial nectar increases consumption of phenolics (Liu et al. 2007). In the case of nicotine, the dose-dependent deterrent effect on honeybees is stronger in dilute artificial nectars (Köhler et al. 2012).

Nectar-feeding birds compensate for low sugar concentrations by consuming greater volumes to maintain energy intake (Nicolson and Fleming 2003, Martínez del Rio et al. 2001). In this study, we found that sunbirds and white-eyes were significantly less tolerant of nicotine in the dilute sucrose solution, which could be beneficial when birds need to avoid excess intake of nectar SM, provided that alternative food sources are available. Our prediction that the two generalist nectar-feeding species would have a higher nicotine tolerance than specialist sunbirds was not supported in the case of white-eyes. Their nicotine tolerance was similar to that of sunbirds on the dilute sucrose concentration, but on $1 \mathrm{M}$ sucrose it was lower. Zosterops species appear to be more sensitive to nicotine in artificial nectar than to phenolics in nectar of A. vryheidensis (Johnson et al. 2006) or in artificial fruit (Stanley and Lill 2001). Compared to the two smaller species, dark-capped bulbuls showed remarkably high nicotine tolerance, being 
repelled only by $300 \mu \mathrm{M}$ nicotine mixed in $1 \mathrm{M}$ sucrose. In addition, they also ingested 4-5 times as much nicotine in relation to sugar intake when presented with $100 \mu \mathrm{M}$ nicotine in 0.25 $M$ sucrose solutions: this nectar concentration is at the lower end of the range in flowers adapted to generalised bird pollinators (Johnson and Nicolson 2008). Our finding that bulbuls tolerate SM in artificial diets better than sunbirds is not unexpected. Aloe vryheidensis nectar is dark and bitter due to the present of phenolics, and in three-choice preference tests (sucrose, hexose and nectar) dark-capped bulbuls accepted this nectar, while amethyst sunbirds rejected it. Bulbuls and white-eyes are effective pollinators of A. vryheidensis, but sunbirds are not (Johnson et al. 2006).

The nicotine tolerance of bulbuls was unaffected by the addition of nicotine to hexose instead of sucrose solutions, although when given a choice between sucrose and hexose solutions in the concentration range 0.1-0.7 M, they prefer hexose (Brown et al. 2010). The predominance of low nectar sucrose in generalised bird pollination systems is not easily explained (Johnson and Nicolson 2008). With the exception mainly of species in the Sturnidae-Muscicapoidea lineage, most specialist and generalist nectarivores have relatively high levels of intestinal sucrase (Fleming et al. 2008). Interestingly, coloured nectars, which tend to be consumed by vertebrates such as generalised bird pollinators, are mostly dominated by hexose sugars, and in some cases secondary metabolites are known to be the cause of the nectar colour (Hansen et al. 2007). Examples are the brown phenolics in nectar of A. vryheidensis (Johnson et al. 2006), red aurones in Nesocodon mauritianus (Campanulaceae) (Olesen et al. 1998) and a purple anthocyanidin in Leucosceptrum canum (Labiatae) (Zhang et al. 2012). In two of these examples, dark SM-containing nectar has been clearly demonstrated to act as a foraging signal to generalised bird pollinators (Johnson et al. 2006, Zhang et al. 2012). Another, though not mutually exclusive, function may be that antimicrobial properties of SM conserve the sugar content of exposed nectars in long-lived flowers (Hansen et al. 2007, Zhang et al. 2012).

The presence of SM in nectar may benefit plant reproduction by manipulating pollinator movements: 'preventing them from loitering' should serve to increase outcrossing (Raguso 2008). High levels of the alkaloid gelsemine reduce the length of insect visits to Gelsemium sempervirens, but also the frequency, and the prediction of benefits to plant reproduction is 
only partially supported (Adler and Irwin 2005). A more recent study on natural populations of G. sempervirens, in which nectar was spiked with extra gelsemine, has confirmed that high alkaloid levels reduce pollinator visitation (Adler and Irwin 2012). High nicotine levels (50 $\mu \mathrm{M}$ ) decreased the feeding frequency and total feeding time of sunbirds in our experiments, but the effect on the duration of single meals was not significant. The much lower levels of nectar nicotine reported for $N$. glauca by Tadmor-Melamed et al. (2004) would not affect the feeding patterns of white-bellied sunbirds, although alkaloid concentrations may differ throughout the broad distribution of this invasive species. The significance of nectar nicotine for plant fitness has is receiving increased attention. Kessler et al. (2012) showed that outcrossing rates are reduced in $N$. attenuata plants in which expression of a gene for nicotine production was silenced. These plants were exposed only to hummingbird pollinators, and variance in nectar nicotine strongly influenced foraging behaviour. However, in a comprehensive study comparing 32 Nicotiana species grown under standard conditions in a greenhouse, Adler et al. (2012) demonstrated a negative correlation between nicotine levels in nectar and the extent of cross-pollination, suggesting that selection by pollinators has reduced the nicotine content of nectar. Obviously, these studies used very different approaches to the question of the ecological role of nicotine in nectar, and further work is essential.

The association between nectar properties and specificity of bird pollinators (Johnson and Nicolson 2008) may extend to SM tolerance. Glendinning (1994) proposed that animals that are exposed to many bitter and potentially toxic compounds in their diet will be less deterred by bitter-tasting compounds. There is some evidence that avian frugivores are relatively tolerant to SM in their fruit diets, compared to many herbivores (Cipollini and Levey 1997, Bairlein 1996) and that consumption of toxic insects by frugivores aids in developing this tolerance (Herrera 1985). Occasional nectarivores show seasonally varying diets, switching to partial nectarivory during periods of high nectar availability, and their diversity and pollinating roles have been under-appreciated (Symes et al. 2008, Botes et al. 2008, Franklin 1999). The birds may be able to cope with nectar SM through their greater tolerance of these compounds and more varied diet than that of nectar specialists. More research on the preferences of avian nectarivores in an ecological setting, and their responses to different classes of SM, is needed 
to clarify the role of nectar SM in ecological interactions with generalist and specialist pollinators.

Acknowledgements - This research was funded by the University of Pretoria and the South African National Research Foundation (NRF). The Gauteng Directorate of Nature Conservation granted permits to capture and house the birds. All animal care procedures and experimental protocols followed the institutional regulations of the University of Pretoria (EC022-09). We thank Jan Celliers Park for permission to catch birds, B. Smit and C. Minnaar for help with mist-netting and fellow students for helping to feed birds. We also thank P.A. Fleming for advice. 


\section{Reference}

Adler, L. S. 2000. The ecological significance of toxic nectar. - Oikos 91: 409-420.

Adler, L. S. and Irwin, R. E. 2005. Ecological costs and benefits of defenses in nectar. Ecology 86: 2968-2978.

Adler, L. S. and Irwin, R. E. 2012. Nectar alkaloids decrease pollination and female reproduction in a native plant. - Oecologia 168: 1033-1041.

Adler, L. S., Seifert, M. G., Wink, M. and Morse, G. E. 2012. Reliance on pollinators predicts defensive chemistry across tobacco species. - Ecol. Lett. 15: 1140-1148.

Bairlein, F. 1996. Fruit-eating in birds and its nutritional consequences. - Comp. Biochem. Physiol. 113A: 215-224.

Botes, C., Johnson, S. D. and Cowling, R. M. 2008. Coexistence of succulent tree aloes: partitioning of bird pollinators by floral traits and flowering phenology. - Oikos 117: 875-882.

Brown, M., Downs, C. T. and Johnson, S. D. 2010. Sugar preferences and digestive efficiency in an opportunistic avian nectarivore, the dark-capped bulbul Pycnonotus tricolor. - J. Ornith. 151: 637-643.

Cipollini, M. L. and Levey, D. J. 1997. Secondary metabolites of fleshy vertebrate-dispersed fruits: adaptive hypotheses and implications for seed dispersal. - Am. Nat. 150: 346372.

Detzel, A. and Wink, M. 1993. Attraction, deterrence or intoxication of bees (Apis mellifera) by plant allelochemicals. - Chemoecology 4: 8-18.

Fleming, P. A., Xie, S., Napier, K. R., McWhorter, T. J. and Nicolson, S. W. 2008. Nectar concentration affects sugar preferences in two Australian honeyeaters and a lorikeet. Biol. Lett. 4: 530-533.

Franklin, D. C. 1999. Opportunistic nectarivory: an annual dry season phenomenon among birds in monsoonal northern Australia. - Emu 99: 135-141.

Geerts, S. and Pauw, A. 2009. African sunbirds hover to pollinate an invasive hummingbirdpollinated plant. - Oikos 118: 573-579. 
Gegear, R. J., Manson, J. S. and Thomson, J. D. 2007. Ecological context influences pollinator deterrence by alkaloids in floral nectar. - Ecol. Lett. 10: 375-382.

Glendinning, J. I. 1994. Is the bitter rejection response always adaptive? - Physiol. Behav. 56: 1217-1227.

Hagler, J. R. and Buchmann, S. L. 1993. Honey bee (Hymenoptera: Apidae) foraging responses to phenolic-rich nectars. - J. Kansas Ent. Soc. 66: 223-230.

Halpern, S. L., Adler, L. S. and Wink, M. 2010. Leaf herbivory and drought stress affect floral attractive and defensive traits in Nicotiana quadrivalvis. - Oecologia 163: 961-971.

Hansen, D. M., Olesen, J. M., Mione, T., Johnson, S. D. and Müller, C. B. 2007. Coloured nectar: distribution, ecology, and evolution of an enigmatic floral trait. - Biol. Rev. 82: 83-111.

Herrera, C. M. 1985. Aposematic insects as six-legged fruits: incidental short-circuiting of their defense by frugivorous birds. - Am. Nat. 126: 286-293.

Herrera, C. M., García, I. M. and Pérez, R. 2008. Invisible floral larcenies: microbial communities degrade floral nectar of bumble bee-pollinated plants. - Ecology 89: 23692376.

Irwin, R. E., Adler, L. S. and Brody, A. K. 2004. The dual role of floral traits; pollinator attraction and plant defense. - Ecology 85: 1503-1511.

Jackson, S., Nicolson, S. W. and Lotz, C. N. 1998. Sugar preferences and "side bias" in Cape sugarbirds and lesser doublecollared sunbirds. - Auk 115: 156-165.

Johnson, S. D., Hargreaves, A. L. and Brown, M. 2006. Dark, bitter-tasting nectar functions as a filter of flower visitors in a bird-pollinated plant. - Ecology 87: 2709-2716.

Johnson, S. D. and Nicolson, S. W. 2008. Evolutionary associations between nectar properties and specificity in bird pollination systems. - Biol. Lett. 4: 49-52.

Kaczorowski, R. L., Gardener, M. C. and Holtsford, T. P. 2005. Nectar traits in Nicotiana section Alatae (Solanaceae) in relation to floral traits, pollinators, and mating system. Am. J. Bot. 92: 1270-1283.

Karasov, W. H., Caviedes-Vidal, E., Hartman Bakken, B., Izhaki, I., Samuni-Blank, M. and Arad, Z. 2012. Capacity for absorption of water-soluble secondary metabolites greater in birds than in rodents. - PLoS ONE 7: e32417. 
Kessler, A. and Halitschke, R. 2009. Testing the potential for conflicting selection on floral chemical traits by pollinators and herbivores: predictions and case study. - Funct. Ecol. 23: 901-912.

Kessler, D., Bhattacharya, S., Diezel, C., Rothe, E., Gase, K., Schöttner, M. and Baldwin, I. T. 2012. Unpredictability of nectar nicotine promotes outcrossing by hummingbirds in Nicotiana attenuata. - Plant J. 71: 529-538.

Kessler, D., Diezel, C. and Baldwin, I. T. 2010. Changing pollinators as a means of escaping herbivores. - Curr. Biol. 20: 237-242.

Kessler, D., Gase, K. and Baldwin, I. T. 2008. Field experiments with transformed plants reveal the sense of floral scents. - Science 321: 1200-1202.

Köhler, A., Pirk, C. W. W. and Nicolson, S. W. 2012. Honeybees and nectar nicotine: deterrence and reduced survival versus potential health benefits. - J. Insect Physiol. 58: 286-292.

Köhler, A., Verburgt, L. and Nicolson, S. W. 2006. Short-term energy regulation of whitebellied sunbirds (Nectarinia talatala): effects of food concentration on feeding frequency and duration. - J. Exp. Biol. 209: 2880-2887.

Liu, F., Chen, J., Chai, J., Zhang, X., Bai, X., He, D. and Roubik, D. W. 2007. Adaptive functions of defensive plant phenolics and a non-linear bee response to nectar components. - Funct.l Ecol. 21: 96-100.

London-Shafir, I., Shafir, S. and Eisikowitch, D. 2003. Amygdalin in almond nectar and pollen - facts and possible roles. - Plant Syst. Evol. 238: 87-95.

Manson, J. S., Otterstatter, M. C. and Thomson, J. D. 2010. Consumption of a nectar alkaloid reduces pathogen load in bumble bees. - Oecologia 162: 81-89.

Manson, J. S., Rasmann, S., Halitschke, R., Thomson, J. D. and Agrawal, A. A. 2012. Cardenolides in nectar may be more than a consequence of allocation to other plant parts: a phylogenetic study of Asclepias. - Funct. Ecol. doi: 10.1111/j.13652435.2012.02039.x.

Martínez del Rio, C., Schondube, J. E., McWhorter, T. J. and Herrera, L. G. 2001. Intake responses in nectar feeding birds: digestive and metabolic causes, osmoregulatory consequences, and coevolutionary effects. - Am. Zool. 41: 902-915.

Moss, C. F. and Dethier, V. G. 1983. Central nervous system regulation of finicky feeding by the blowfly. - Behav. Neurosci. 97: 541-548. 
Nattero, J. and Cocucci, A. A. 2007. Geographical variation in floral traits of the tree tobacco in relation to its hummingbird pollinator fauna. - Biol. J. Linn. Soc. 90: 657-667.

Nicolson, S. W. and Fleming, P. A. 2003. Energy balance in the whitebellied sunbird Nectarinia talatala: constraints on compensatory feeding, and consumption of supplementary water. - Funct. Ecol. 17: 3-9.

Olesen, J. M., Ronsted, N., Tolderlund, U., Cornett, C., Molgaard, P., Madsen, J., Jones, C. G. and Olsen, C. E. 1998. Mauritian red nectar remains a mystery. - Nature 393: 529-529.

Raguso, R. A. 2008. The "invisible hand" of floral chemistry. - Science 321: 1163-1164.

Raguso, R. A., Levin, R. A., Foose, S. E., Holmberg, M. W. and McDade, L. A. 2003. Fragrance chemistry, nocturnal rhythms and pollination "syndromes" in Nicotiana. Phytochemistry 63: 265-284.

Singaravelan, N., Nee'man, G., Inbar, M. and Izhaki, I. 2005. Feeding responses of free-flying honeybees to secondary compounds mimicking floral nectars. -31: 2791-2804.

Skead, C. J. 1967. Sunbirds of Southern Africa, Cape Town, A.A. Balkema.

Stanley, M. C. and Lill, A. 2001. Response of silvereyes (Zosterops lateralis) to dietary tannins: the paradox of secondary metabolites in ripe fruit. - Aust. J. Zool. 49: 633-640.

Stephenson, A. G. 1982. Iridoid glycosides in the nectar of Catalpa speciosa are unpalatable to nectar thieves. - J. Chem. Ecol. 8: 1025-1034.

Steppuhn, A., Gase, K., Krock, B., Halitschke, R. and Baldwin, I. T. 2004. Nicotine's defensive function in nature. - PLoS Biol. 8: e217.

Strauss, S. Y. 1997. Floral characters link herbivores, pollinators, and plant fitness. - Ecology 78: $1640-1645$.

Symes, C. T., Nicolson, S. W. and McKechnie, A. E. 2008. Response of avian nectarivores to the flowering of Aloe marlothii: a nectar oasis during dry South African winters. - J. Ornith. 149: 13-22.

Tadmor-Melamed, H., Markman, S., Arieli, A., Distl, M., Wink, M. and Izhaki, I. 2004. Limited ability of Palestine sunbirds Nectarinia osea to cope with pyridine alkaloids in nectar of tree tobacco Nicotiana glauca. - Funct. Ecol. 18: 844-850. 
Zhang, F.-P., Cai, X.-H., Wang, H., Ren, Z.-X., Larson-Rabin, Z. and Li, D.-Z. 2012. Dark purple nectar as a foraging signal in a bird-pollinated Himalyan plant. - New Phytol. 193: 188-195. 
Table 1: Summary of statistical analyses for nicotine tolerance. Different nicotine and sugar concentrations were offered to 10 whitebellied sunbirds, 7 Cape white-eyes, and 9 dark-capped bulbuls. Nicotine tolerances (after arcsine square root transformation) were compared with 0.5 (indicating tolerance) by one-sample $t$-test. P-values in bold are $<0.05$, but only those indicated with an asterisk (*) are still statistically significant after a sequential Bonferroni correction.

\begin{tabular}{|c|c|c|c|c|c|c|c|c|c|c|c|c|c|c|c|c|}
\hline \multirow{4}{*}{$\begin{array}{l}\text { Species } \\
\text { Sugar type } \\
\text { Sugar } \\
\text { concentration } \\
\text { (M) } \\
\text { Statistical results }\end{array}$} & \multirow{2}{*}{\multicolumn{4}{|c|}{$\begin{array}{l}\text { White-bellied sunbird } \\
\text { Sucrose }\end{array}$}} & \multirow{2}{*}{\multicolumn{4}{|c|}{$\begin{array}{l}\text { Cape white-eye } \\
\text { Sucrose }\end{array}$}} & \multicolumn{8}{|c|}{ Dark-capped bulbul } \\
\hline & & & & & & & & & & & & & Hexose & & & \\
\hline & \multicolumn{2}{|l|}{0.25} & \multicolumn{2}{|l|}{1} & \multicolumn{2}{|l|}{0.25} & \multicolumn{2}{|l|}{1} & \multicolumn{2}{|l|}{0.25} & \multicolumn{2}{|l|}{1} & \multicolumn{2}{|l|}{0.25} & \multicolumn{2}{|l|}{1} \\
\hline & $t_{9}$ & $\mathrm{P}$ & $t_{9}$ & $\mathrm{P}$ & $\mathrm{t}_{6}$ & $P$ & $\mathrm{t}_{6}$ & $\mathrm{P}$ & $t_{8}$ & $\mathrm{P}$ & $t_{8}$ & $P$ & $\mathrm{t}_{8}$ & $P$ & $\mathrm{t}_{8}$ & $\mathrm{P}$ \\
\hline \multicolumn{17}{|l|}{$\begin{array}{l}\text { Nicotine } \\
\text { concentrations } \\
(\mu \mathrm{M})\end{array}$} \\
\hline 0.1 & -0.82 & 0.432 & -0.18 & 0.862 & -1.54 & 0.175 & -1.22 & 0.269 & & & & & & & & \\
\hline 0.3 & & & & & & & & & 1.85 & 0.101 & -0.55 & 0.596 & 0.00 & 0.997 & 0.56 & 0.591 \\
\hline 0.6 & -1.22 & 0.254 & -0.48 & 0.640 & -1.31 & 0.240 & -1.12 & 0.304 & & & & & & & & \\
\hline 1 & & & & & & & & & 0.65 & 0.532 & 1.04 & 0.328 & -1.28 & 0.236 & 0.61 & 0.557 \\
\hline 1.5 & -1.12 & 0.292 & 1.24 & 0.247 & -1.11 & 0.310 & -4.18 & $0.006^{*}$ & & & & & & & & \\
\hline 3 & -2.54 & 0.032 & -2.26 & 0.050 & -4.05 & 0.007 & -11.55 & $0.000^{*}$ & -0.92 & 0.384 & -1.02 & 0.337 & 1.21 & 0.262 & -1.88 & 0.096 \\
\hline 7 & -3.40 & 0.008 & -1.60 & 0.143 & -5.06 & $0.002^{*}$ & -3.86 & $0.008^{*}$ & & & & & & & & \\
\hline 10 & & & & & & & & & 0.07 & 0.946 & 2.20 & 0.059 & -0.28 & 0.789 & 1.83 & 0.105 \\
\hline 15 & -9.34 & $0.000^{*}$ & -1.41 & 0.193 & -11.89 & $0.000^{*}$ & -2.58 & 0.042 & & & & & & & & \\
\hline 30 & & & & & & & & & -0.58 & 0.579 & -1.11 & 0.300 & -0.83 & 0.428 & -0.63 & 0.547 \\
\hline 40 & -12.73 & $0.000^{*}$ & -1.65 & 0.133 & -9.56 & $0.000^{*}$ & -6.68 & $0.001^{*}$ & & & & & & & & \\
\hline 100 & -45.59 & $0.000^{*}$ & -5.79 & $0.000^{*}$ & -19.02 & $0.000^{*}$ & -7.96 & $0.000^{*}$ & -6.37 & 0.000 & -0.30 & 0.773 & -4.76 & 0.001 & 0.90 & 0.395 \\
\hline 300 & -65.74 & $0.000^{*}$ & -8.79 & $0.000^{*}$ & -27.54 & $0.000^{*}$ & -10.84 & $0.000^{*}$ & -7.52 & 0.000 & -2.58 & $0.032^{*}$ & -14.03 & 0.000 & -5.49 & 0.001 \\
\hline
\end{tabular}




\section{Figure legends}

Figure 1: Nicotine tolerance of birds offered different nicotine and sucrose concentrations. Data are for (a) white-bellied sunbirds C. talatala $(n=10)$, (b) Cape white-eyes Z. virens ( $n$ $=7$ ) and (c) dark-capped bulbuls P. tricolor $(n=9)$. Data are from pair-wise preference tests with sucrose-only $(0.25 \mathrm{M} \bullet$ or $1 \mathrm{M} \circ)$ solutions and nicotine-containing diets (the same sucrose concentration with nicotine: $0.1-300 \mu \mathrm{M}$ ). A value of 0.5 (dotted line) indicates nicotine tolerance. Values are means \pm SE, SE partly omitted for clarity.

Figure 2: Effect of sugar type on nicotine tolerance of dark-capped bulbuls $P$. tricolor $(n=9)$. Birds were offered pairs of sucrose or hexose $(0.25 \mathrm{M} \bullet$ or $1 \mathrm{M} \circ)$ solutions and different nicotine concentrations $(0.3-300 \mu \mathrm{M})$ mixed in the same sugar solution. A value of 0.5 (dotted line) indicates nicotine tolerance. Values are means \pm SE, SE partly omitted for clarity.

Figure 3: Nicotine intake ( $\mu \mathrm{g}) /$ sugar intake (g) for of nectar-feeding birds offered two nicotine and two sucrose concentrations. Nicotine $(100 \mu \mathrm{M}$ and $300 \mu \mathrm{M})$ was mixed in $0.25 \mathrm{M}$ sucrose (a) and in $1 \mathrm{M}$ sucrose (b). SB = white-bellied sunbirds C. talatala $(n=10), \mathrm{WE}=$ Cape white-eyes Z. virens $(n=7)$ and $\mathrm{BB}=$ dark-capped bulbuls $P$. tricolor $(n=9)$. Consumption was measured over a $6 \mathrm{~h}$ period. Bars are mean values $\pm \mathrm{SE}$.

Figure 4: Effect of nicotine on food intake and short-term feeding patterns of white-bellied sunbirds C. talatala $(n=9)$. Data shown as $(a)$ sugar intake $(\mathrm{g} / \mathrm{h})$; (b) feeding frequency (events/h); (c) feeding duration (s); and (d) total feeding time ( $\mathrm{s} / \mathrm{h}$ ). Birds were fed different nicotine concentrations in $0.63 \mathrm{M}$ sucrose for $6 \mathrm{~h}$. Bars are mean values $\pm \mathrm{SE}$. 


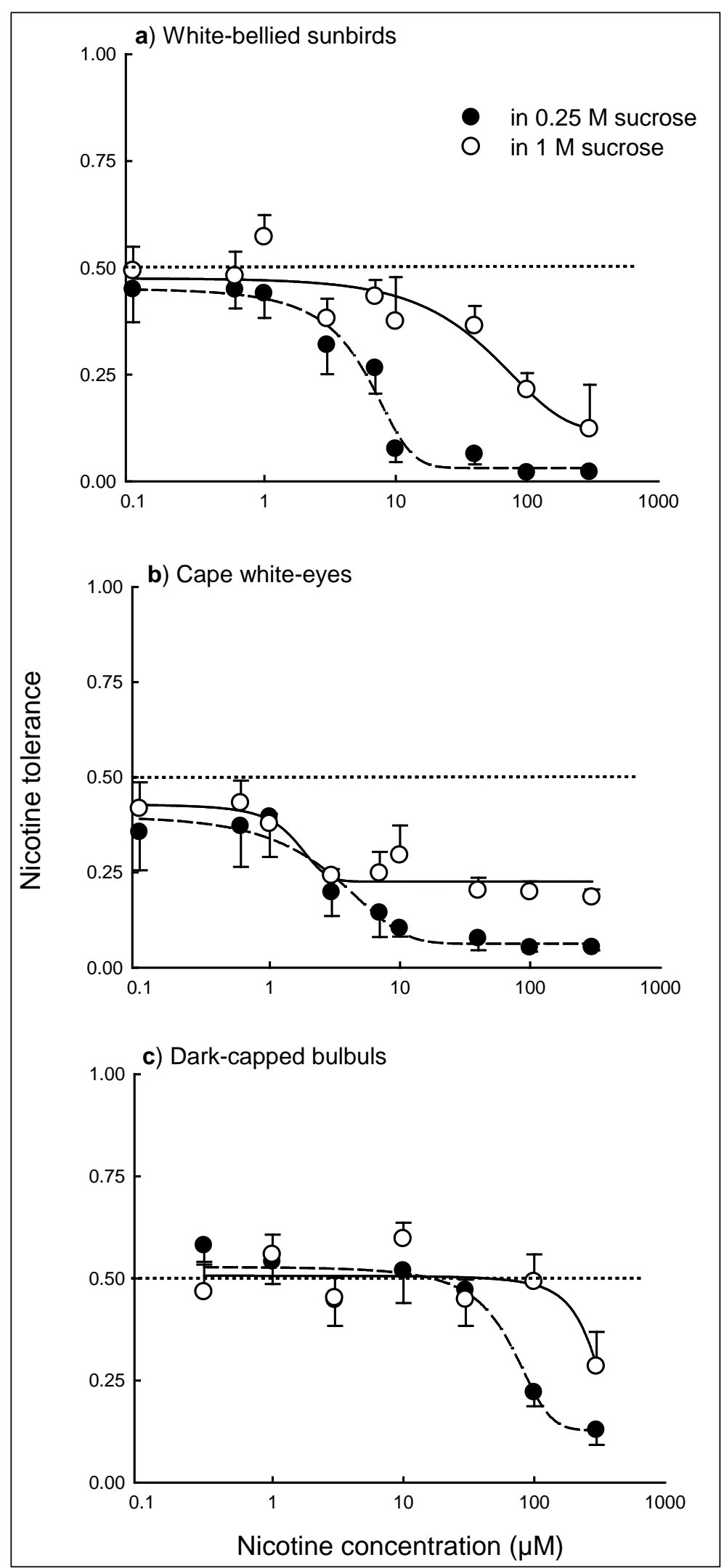

Figure 1 


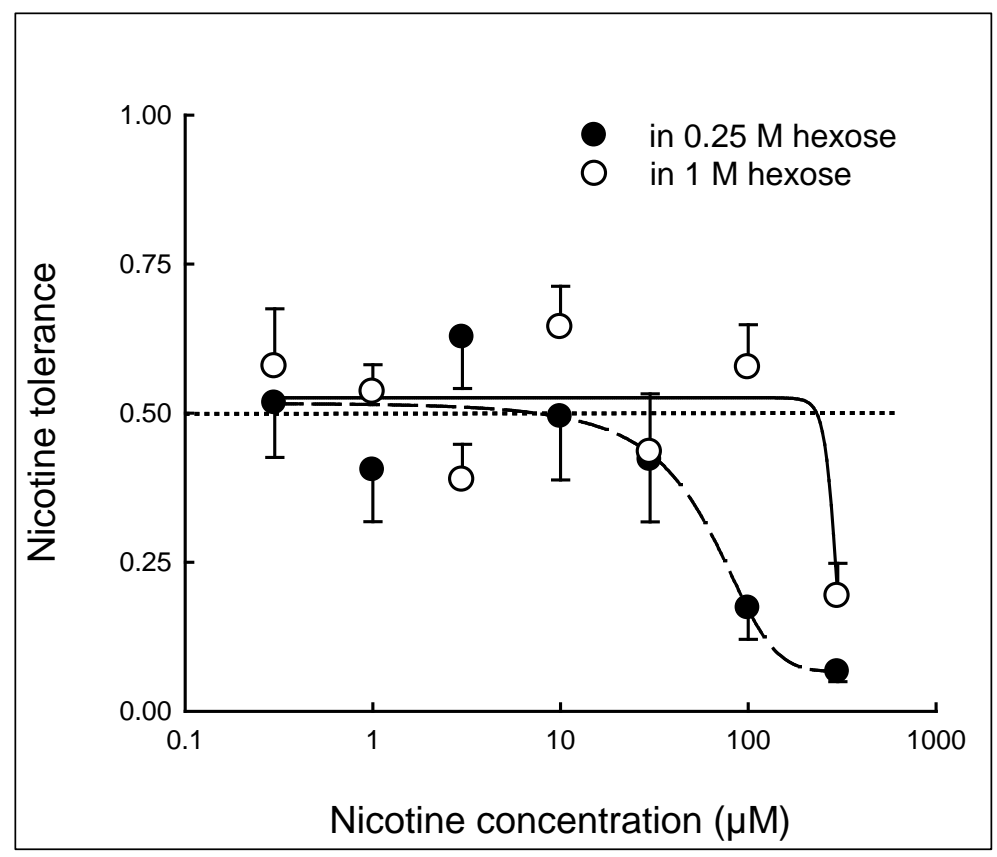

Figure 2 


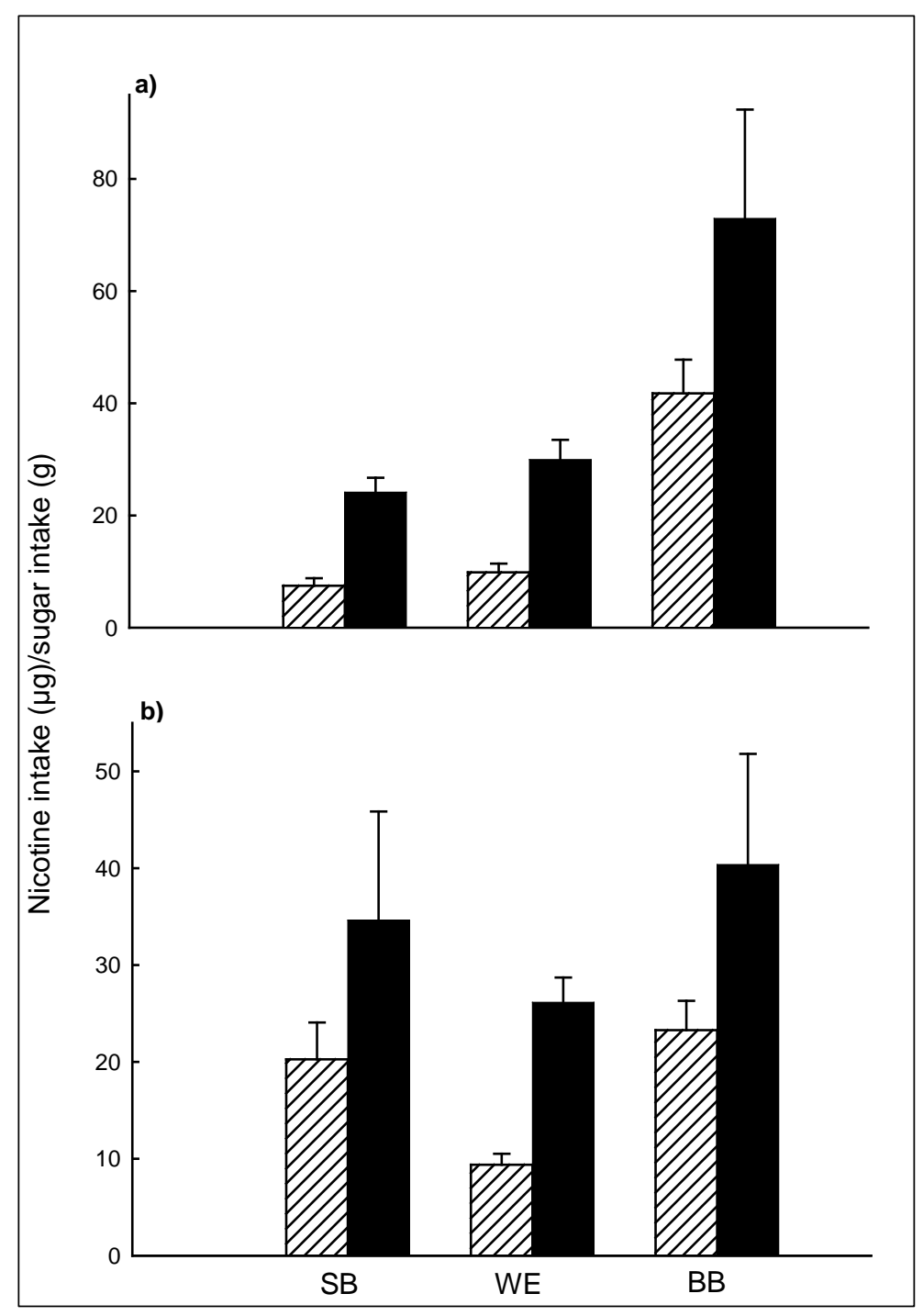

Figure 3 
ll. 